\title{
SOCIAL ISOLATION CHALLENGE: RUSSIAN CONTEXT
}

\author{
Aleksander L. Strizoe \\ Volgograd State University, Volgograd, Russian Federation
}

\begin{abstract}
The article considers the main trends and features of the impact of social isolation measures in a global pandemic on the life of modern society. The author notes that the practice of implementing measures of social isolation distinguishes certain social strata, pushing others to the periphery of managerial attention and support; aggravates feelings of social inequality of opportunity, changes space and intensity of individual and social mobility; affects the authority of local and regional government and attitudes towards them. The article describes various aspects and difficulties of individual and social adaptation to the pandemic. The carried out comparative analysis of European and Russian sociocultural context, in which social challenges of the pandemic are manifested, shows their common features: aggravation of problems of social adaptation, different degrees of readiness for it, an asynchronous development of integration processes, an authoritarian-conservative turn in the mass consciousness. The characteristic of the main trends of changes in consciousness and behavior is given, in which the response of Russian society to the challenges of new living conditions and the pandemic reformatting of the social communications space is manifested. The attention to the multidirectional character of adaptation strategies of the population is drawn. The author expresses the opinion that the choice of the optimal variant of society's adaptation to global environmental, including pandemic, challenges is determined both by the elite's ability to transform social institutions and by a change in the dominant personality type. An atomized type of individual, focused on the values of early modernity, in whose subconsciousness authoritarian-paternalistic attitudes are preserved, should be replaced by a type of personality, with qualities and abilities corresponding to the imperatives of a complex and dynamically changing modern society.
\end{abstract}

Key words: pandemic, social isolation, social challenge, social adaptation, social solidarity, social fairness, authoritarianism, personality.

Citation. Strizoe A.L. Social Isolation Challenge: Russian Context. Logos et Praxis, 2021, vol. 20, no. 2, pp. 65-73. (in Russian). DOI: https://doi.org/10.15688/lp.jvolsu.2021.2.8

УДК 316:364-785.14:616-036.21

ББК 60.524 .125

\section{ВЫЗОВ СОЦИАЛЬНОЙ ИЗОЛЯЦИИ: РОССИЙСКИЙ КОНТЕКСТ}

\author{
Александр Леонидович Стризое \\ Волгоградский государственный университет, г. Волгоград, Российская Федерация.
}

\begin{abstract}
Аннотация. В статье показаны основные направления и особенности воздействия мер социальной изоляции в условиях глобальной пандемии на жизнь современного общества. Автор отмечает, что практика реализации мер социальной изоляции выделяет определенные социальные слои, оттесняя другие на периферию управленческого внимания и поддержки; усугубляет ощущения социального неравенства возможностей, изменяет пространство и интенсивность индивидуальной и социальной мобильности; влияет на авторитет местной и региональной власти и отношение к ней. В статье дана характеристика разным аспектам и трудностям индивидуальной и социальной адаптации к пандемии. В ходе проведенного сравнительного анализа европейского и российского социокультурного контекста, в котором проявляются социальные вызовы \& пандемии, выделены их общие черты: обострение проблем социальной интеграции, разная степень готовности к ней, асинхронность развития интеграционных процессов, авторитарно-консервативный поворот в массовом сознании. Дана характеристика основных тенденций изменения сознания и поведения, в которых (?) проявляется ответ российского общества на вызовы новых условий жизни и пандемического переформати-
\end{abstract}




\section{ИЗОЛЯЦИЯ В ОТКРЫТОМ ОБЩЕСТВЕ}

рования пространства социальных коммуникаций. Автор обращает внимание на разнонаправленность адаптационных стратегий населения. В статье высказано мнение о том, что выбор оптимального варианта адаптации общества к глобальным экологическим, в том числе и пандемическим вызовам, определяется как способностью элиты к трансформации социальных институтов, так и изменением доминирующего типа личности. Тип атомизированного индивида, ориентированный на ценности раннего модерна, в подсознании которого сохраняются авторитарно-патерналистские установки, должен быть замещен типом личности, качества и способности которого соответствовали бы императивам сложного и динамично изменяющегося современного общества.

Ключевые слова: пандемия, социальная изоляция, социальный вызов, социальная адаптация, социальная солидарность, социальная справедливость, авторитаризм, личность.

Цитирование. Стризое А. Л. Вызов социальной изоляции: российский контекст // Logos et Praxis. 2021. - T. 20, № 2. - C. 65-73. - DOI: https://doi.org/10.15688/lp.jvolsu.2021.2.8

Глобальная пандемия коронавируса оказала существенное влияние на жизнь общества начала XXI века. Одним из проявлений такого влияния стало изменение ландшафта социальных связей, пространства, формата и режима общения людей в условиях использования мер социальной изоляции. Эти меры стали своеобразным вызовом социокультурной реальности, поскольку в них воплотилось воздействие на общество не только силы государства и медико-гигиенических императивов, но и принудительное воздействие механизмов общественной дисциплины - внушения, стереотипизации, подражания, опривычивания и административно-экономического принуждения.

Введение этих мер заметно изменило повестку дня для общественного мнения и СМИ. Важнейшей проблемой стало обоснование необходимости и оправданности социальной изоляции, а также справедливости тех форм ее осуществления, которые были предложены обществу. Сложности такого обоснования были связаны, прежде всего, с недостатком знаний о природе самого вируса, его контагиозности, симптоматике и возможных последствиях заражения. Социальный контекст использования медико-биологической информации, связанной с пандемией, определялся тем, что она была особо значима для определенных социально-демографических групп: людей зрелого и пожилого возраста, страдающих определенными хроническими заболеваниями, имеющих ограниченный доступ к качественным медицинским услугам, жителям депрессивных в социально-экономическом смысле районов и территорий. Меры социальной изоляции, изменив привычный уклад жизни, создали для них дополнительные труд- ности, повысили их социальную уязвимость. Это поставило вопрос о дифференциальной диагностике не только в медицинском смысле, но и, как справедливо подчеркивает А.В. Рубцов, «состояния здоровья» различных социальных организмов [Рубцов 2020, 23]. Адресность пандемической угрозы привела к тому, что коммуникационные ограничения, а также внимание властей, работников здравоохранения и учреждений социальной защиты коснулись одних социальных слоев, оттеснив другие на периферию управленческого внимания и поддержки.

Меры социальной изоляции сказались на работе весьма важной для современного общества сфере сервиса, а также малого и среднего бизнеса, изменив организацию труда, все пространство коммуникаций производителей и потребителей разнообразных работ, товаров и услуг. Дистантный режим работы и функционирования таких социальных институтов, как образование, культура, рекреация, был сопряжен с новыми проблемами организации, учета и контроля труда. Домашний режим работы фактически стирал границы рабочего и свободного времени, делая рабочий день ненормированным [Шипилов 2020, 137]. При этом рост трудовой нагрузки в условиях дистанта не исключал снижения качества получаемых результатов. Далеко не всем формально включенным в сферу дистантного взаимодействия оно оказалось фактически доступно в силу отсутствия компьютеров и иных электронных средств или сбоев в их работе. Эти, казалось бы, сугубо технические проблемы, часто создавали негативный эмоциональный фон, усугубляли ощущения социального неравенства возможностей, уязвимости и дискриминации. Социальная изоляция отразилась 
и на современном пространстве индивидуальной и социальной мобильности, превратив пользование общественным транспортом в зону повышенного риска и угрозы заражения. Масштабным изменениям подверглись также сферы публичной коммуникации: затруднив общение, пандемия внесла в эти пространства новые напряженности, риски, морально-психологический дискомфорт. Изменения в организации досуга оказались весьма травматичны для социально-психологического самочувствия и болезненны для привычного образа жизни самых разных групп населения.

Реализация этих мер, особенно в крупных городах и мегаполисах, негативно повлияла на авторитет и позиции местной и региональной власти, которую многие подозревали в неоправданном ограничении социальной и гражданской активности, вторжении в частную жизнь, выборе неверных социальных приоритетов и способов реагирования. В условиях глобального масштаба пандемии эти подозрения имели объективное основание. Ошибки в дифференциальной диагностике ситуации приводили к ошибочным обобщениям, когда «генерализации подвергается не то, что нужно, а то, что бросается в глаза как якобы лишенное различий» [Рубцов 2020, 24]. Сомнения в справедливости коммуникативных ограничений провоцировали появление разного рода конспирологических объяснений, как самой пандемии, так и мер по противодействию ей. Это провоцировало, с одной стороны, появление ковид-диссиденства, отрицавшего существование пандемической угрозы, призывавшего к саботажу мер, направленных против нее, с другой же, возник пандемический алармизм, также оказывавший негативное воздействие на общественные настроения.

Затронув процессы социализации, меры социальной изоляции не только воздействовали на формы коммуникации и каналы передачи социального опыта, но и поставили вопрос об адаптации личности и общества к новым условиям. Сложность такой адаптации была связана не только со спецификой поля рисков, угрожающих медико-биологической безопасности личности и общества, но с их временной неопределенностью. В ситуации, когда число волн пандемии, их сила и продолжитель- ность оценивались весьма приблизительно, возникала перспектива постоянного присутствия вирусной угрозы, требующая от разных поколений людей научиться жить в новых условиях. С одной стороны, все это поставило вопросы о социальном статусе личности, ее положении в социальном пространстве и социальном самочувствии, связанные с самоопределением в обществе, с выбором направлений и сфер социальных контактов и взаимодействий. С другой - вопросы о личной автономии и выборе жизненной траектории, о личном достоинстве, ощущении самого себя и собственной идентичности. Ответы на них имеют в своем основании в большей или меньшей мере проявленную мировоззренческую и смысложизненную рефлексию. Ее отражением стала постановка вопроса о диалектической взаимосвязи биополитики, проявлением которой стали меры социальной изоляции, и обеспечения гуманитарной безопасности человека [Кукарцева (Гласер), Ивлев, Новик 2021].

Ответ и общества, и отдельных личностей на вызов социальной изоляции определяется, наряду с другими факторами, локальным социокультурным контекстом, опытом и логикой предшествующего социально-исторического развития, формирующими повестку дня, актуальную для конкретных регионов и сообществ. Социальная изоляция, с одной стороны, обостряет восприятие этой локальной специфики, отделяя ее от влияния глобальных информационно-технологических, экономических и политических факторов. С другой - будучи общей для большинства государств формой реакции на глобальный характер пандемии, изоляция указывает на сходство основных культурных форм противостояния этой опасности и адаптации к ней. Таким образом, столкновение глобального и локального культурных контекстов в процессе обсуждения и практической реализации актуальной повестки дня выявляет ее проблемность, стимулируя поиски путей разрешения кризиса.

Европейская философия предлагает нам различные ракурсы видения и рефлексии локальных социокультурных ландшафтов и приоритетов развития. В этой панораме мнений и оценок для нас интересен немецкий взгляд, позволяющий увидеть, как общие, так и специфически российские моменты социальных 
последствий пандемии и связанной с ней изоляции. Этот взгляд представлен Ю. Хабермасом, поставившим вопрос о перспективах социальной интеграции в общеевропейском и германском национально-государственном масштабе в условиях, когда пандемия и социальная изоляция умножили барьеры между странами, регионами, сообществами и социальными группами [Habermas web]. Сходная проблема существует и в России. Она обусловлена не только остротой проблемы интеграции постсоветского пространства и важностью предотвращения региональной и этнокультурной разобщенности огромного внутрироссийского пространства. Пандемия поставила вопрос о преодолении барьеров социально-экономического неравенства, о разрушении резерваций бедности и маргинальности, о демократизации доступа к мерам предотвращения и профилактики инфицирования, к качественным медицинской помощи и образованию детей и молодежи и социальной поддержке.

Ю. Хабермас признает различный уровень готовности обществ к решению интеграционных задач. По его мнению, ограничения периода пандемии показали, что, хотя «немецкое и европейское воссоединение были связаны друг с другом, словно сообщающиеся сосуды», «для бывших граждан ГДР, выросших в другой политической среде, тема единой Европы не была столь же важной и значимой, как для граждан “старой” ФРГ». В то же время, выявилась асинхронность процессов социальной интеграции отдельных обществ, когда «экономически обоснованные опасения краха панъевропейского проекта... стали достаточно сильны, чтобы изменить приоритеты», а опасность, исходящая «от давно поменявшейся геополитической картины мира... подвергает испытаниям демократический строй и культурную идентичность европейцев» [Habermas web].

Трудности социальной интеграции, описанные Ю. Хабермасом, не являются специфически европейскими. Они представляют собой проявления таких универсальных особенностей протекания социальных процессов как многоуровневый характер, неравномерность протекания, социокультурная обусловленность. Глобальный характер пандемичес- кой опасности выявил, как в Европе, так и в России, трудности внутренней консолидации сообществ, координации и синхронизации государственной политики и управления на различных уровнях социальной организации. Ситуация с восприятием россиянами угроз и рисков пандемии подтвердила справедливость замечания Ю. Хабермаса о роли среды и формирующегося в ней социального опыта как факторов, способствующих или препятствующих согласованным совместным действиям людей, массовидности их социальных реакций. Если в относительно этнически однородной Германии мозаичность социального опыта и культуры обусловлена преимущественно политико-идеологическими факторами, то в российских условиях такая мозаичность является отражением этноконфессиональных и территориально-поселенческих различий. Они могут провоцировать неадекватные реакции, в том числе в духе ковид-диссидентства, на унифицирующие требования социальной изоляции и их императивный характер. Эффективную адаптацию к требованиям социальной изоляции часто затрудняют отмеченные философом различные скорости протекания экономических, геополитических и институционально-политических изменений. В Российских условиях действие всех этих объективных тенденций усиливает фрагментацию социальной структуры и атомизацию общества, углубляет и без того существенные различия в проявлениях социальной солидарности на микро и макроуровне, что существенно ослабляют возможности противостояния пандемии.

Ю. Хабермас обратил внимание на совпавший с периодом пандемии консервативный поворот в немецкой политике и общественном мнении. Действительно, санитарно-гигиеническая аргументация социальной изоляции усилилась в Германии политико-идеологическим изоляционизмом, поскольку «впервые за всю историю германской политики» в ней появилась и успешно закрепилась право-авторитарная политическая сила («Альтернатива для Германии»), «сочетающая критику европейской интеграции с доселе невиданным радикальным национализмом неприкрытым и этноцентрически окрашенным» [Habermas web]. Такой поворот явился реакцией не только на романтически-оптимистическое восприя- 
тие глобализации с ее безразличием к национально-культурной специфике. К угрозам сохранения немецкой идентичности пандемия добавила угрозы экзистенциального характера. Поворот к консерватизму и архаической автаркии, движение к пробуждению и актуализации инстинкта самосохранения, к зову голоса «крови и почвы» стал традиционалистским антропокультурным ответом на угрозу здоровью и физическому существованию. Усиление авторитарно-консервативных настроений в период пандемии характерно и для российского общества, хотя проблемы идентичности, отношения к мигрантам и структурам евроинтеграции возникают здесь в контексте иной повестки дня. Помимо международных и геополитических факторов мировоззренческое и идеологическое самоопределение россиян осуществляется в условиях кризиса многократных, либерально ориентированных попыток реформирования институтов социальной сферы (в том числе здравоохранения), совпавших с пандемией. Применительно к обсуждаемой нами теме социальной изоляции в условиях пандемии консервативные ценности и установки актуальны в плане формирования отношения личности к своим здоровью и жизни, к личной автономии, взаимосвязям с социальным окружением и государством. Следствием этого являются сходные по своей векторной направленности, смыслу и значению социальные реакции, возникающие в самых разных культурных средах и сообществах.

Очертив специфику российского социального контекста, в котором обнаруживает себя глобальная опасность пандемии, обратимся к характеристике проявившихся ответов российского общества на вызовы новых условий жизни и пандемического переформатирования пространства социальных коммуникаций. Как отмечает Р.Г. Апресян, метафорой этих ответов стало пришедшее из актуального в 2020 г. политического дискурса слово «обнуление», которое «обоснованно ассоциируется не только с политическими процессами, но и с тем опытом, который мы переживаем как наблюдатели, участники и жертвы пандемии Covid-19. Мы оказались ограниченными в своих возможностях» [Лескова web]. По его мнению, социальные реакции в этой ситуации сходны с ответами на иные экологические вызовы. Они соответствуют двум общим принципам - «принципу снижения негативных эффектов и принципу адаптации», причем последний - «это социально-этический принцип, отвечающий принципу самосохранения» [Лескова web]. Поскольку в жизни российского общества реализация этих двух принципов неразрывно связана со статусами и позициями индивидов, слоев и групп в социальном пространстве, их доступом к социальным благам и ресурсам, реально достигаемые ими результаты будут различны, а иногда и противоположны.

Отмеченные выше различия в степени адаптации на разных уровнях организации социальной жизни, проявляются и в России. Лишь около трети россиян (31 \%) назвали нормальным и спокойным общее положение дел в стране. На уровне конкретных регионов позитивные оценки заметно выше (45 \%), ситуацию по месту своего жительства нормальной и спокойной считают $55 \%$ опрошенных. [Четверикова web]. Это можно объяснить не только разнообразием условий, локальной спецификой и инертностью повседневного уклада жизни, но и естественностью и успешностью приспособительных изменений, их согласованностью со здравым смыслом.

Социологи и наблюдатели признают факт роста солидарности и взаимопомощи в поведении людей в период пандемии. Об этом говорят до $40 \%$ опрошенных. Причем в возрастной группе от 25 до 34 лет так считают 48 \% респондентов. Более половины опрошенных (56 \%) отмечают, что «единство между людьми усилилось из-за пандемии коронавируса и карантина» [Солидарность на фоне пандемии... web]. Эти ориентации сильнее всего проявились в волонтерской и добровольческой деятельности, на что указали $59 \%$ респондентов. Показательно, что в возрастных группах от 18 до 24 лет и старше 60 лет, представляющих соответственно потенциальных участников движения и его адресатов, этот показатель выше (64 \%). Наконец, большинство россиян (71 \%) указали на другие формы взаимопомощи, признав, что в ушедшем 2020 г. они «совершали какое-либо общественно полезное дело, помогали другим» [Солидарность на фоне пандемии... web]. Проявлением ори- 
ентации на взаимную поддержку является и стремление к самоорганизации, которое наблюдается, например, у создателей и активистов $\mathrm{HКO,} \mathrm{стихийно} \mathrm{вступивших} \mathrm{в} \mathrm{период} \mathrm{пандемии}$ на путь создания региональных объединений и координации собственных действий. Вместе с тем в обществе проявили себя и настроения эскапизма, ухода в частную жизнь, замыкания в кругу собственных проблем. Своеобразной формой ответа на ограничения периода пандемии стало участие некоторых групп молодых россиян в протестном движении. Можно предположить, что помимо радикально настроенного меньшинства, в его рядах оказались те, кто был обделен вниманием властей и не ощутил поддержки с их стороны в решении собственных житейских проблем.

В социокультурном плане адаптация к вызовам социальной изоляции проявилась в различных практиках элитарной и массовой культуры. Нравственно-психологические коллизии социокультурной адаптации точно выразил Р.Г. Апресян: «Человек вроде как “звучит гордо”. А тут приходится приспосабливаться, уступать что-то из своей идентичности, менять привычки» [Лескова web]. Это обстоятельство определило некоторую недооценку пандемической угрозы у значительной части общества и заторможенный характер ее ответных реакций. Критически воспринимая или даже отторгая «чужеродные» внешние, к тому же ограничительные, воздействия властей и связанных с ними СМИ, культура «верхов» и «низов» исходила из веры в свою автономию и неуязвимость, а также из убежденности в незыблемости «двойных стандартов» как основы российской действительности. Если у «верхов» эта позиция опиралась на их материальные ресурсы и чувство вседозволенности, то «низы» часто уповали «на авось», позволяющий отсидеться в изоляции или обойтись «народными средствами» профилактики и предупреждения инфицирования. Инерция подобного рода обнаруживает себя и в отношении россиян к вакцинации. Она усугубляется тем, что перестройка и реорганизация институтов здравоохранения не устранила проблемы с доступностью и качеством массовой медицинской помощи.

Сложности социокультурной адаптации обусловлены не только тревогами граждан, связанными с сохранением здоровья, но и озабоченностью будущим детей и молодежи. Соотношение пессимистических прогнозов, предрекающих большие проблемы системе образования, и оптимистических надежд на улучшения составляет здесь $70 \%$ к $5 \%$, в то время как применительно к системе здравоохранения оно выражается как 51 \% и 27 \% [Четверикова web]. Оптимизм в оценках стабильности ситуации и позитивных изменений в отношении людей дополняется алармистскими (до $30 \%$ тревожности) и катастрофическими (до 10 \%) настроениями части общества. К тому же уровень позитивных оценок изменений в повседневности (отношения в семье, поиски работы, адаптация к дистантной ее организации и проч.) не превышает 5-8 \%, дополняясь таким же и даже более высоким уровнем негативных оценок (до 10$13 \%$ ) [Четверикова web].

Противоречивость и разнонаправленность социокультурной адаптации проявляются и в отношении к виртуальной реальности. Ситуация пандемии еще раз напомнила обществу о том, что «незримое воздействие цифровой среды несравнимо больше влияет на человека, нежели им отслеживается» [Савчук 2020, 84]. В «доковидную» эпоху погружение в нее было преимущественно делом спонтанным и добровольным. Заданные и контролируемые извне дистантные технологии труда и образования изменили ситуацию. Заменяя живой, непосредственный контакт, образующий ткань социальных связей, общением в интернет-среде, компьютерные технологии в условиях социальной изоляции формируют новые общности вовлеченных в коммуникацию, создают новый, достаточно напряженный для участников режим общения, замещают одни условности взаимодействия другими, требующими новых способностей и компетенций. Дистантное обучение, как и работа на дому, потребовали от человека способности к самоорганизации, умения отсекать избыточную информацию. Все это стимулирует выработку нового взгляда на соотношение преимуществ и недостатков реальной и виртуальной коммуникации.

Режим социальной изоляции изменил социальное самочувствие личности, оказав тем самым влияние и на отношения человека и 
общества с институтами власти и управления. Усталость от внешних ограничений и контроля, невозможность снятия стресса и напряжения привычными способами усилили апатию и раздраженность, перерастающую в агрессивность, что в конечном счете заметно повысило конфликтность социальной жизни. Описывая это деструктивное воздействие, Дж. Агамбен констатирует: «Люди настолько привыкли жить в условиях вечного кризиса и вечного чрезвычайного положения, что, кажется, не замечают, что их жизнь сведена к чисто биологическому состоянию и лишилась не только всех социальных и политических свойств, но и человеческих и эмоциональных» [Каким мир станет... web]. Используя для обозначения этой «натурализации» человеческого бытия метафору «голой жизни», Дж. Агамбен, по сути дела, описывает ситуацию, когда инстинктивное, бессознательное, слепое начало заявляет о себе как в индивидуальном, так и в социальном бытии. К сходным выводам приходят и социологи, изучающие мобильность в период пандемии: «Можно сказать, что горожане неожиданно для себя и, возможно, впервые в своей жизни открывают глубины своего социобиологического Я» [Покровский, Макшанчикова, Никишин 2020, 61].

Однако инстинктивное бегство от опасности лишь один из возможных вариантов реакции. Другим проявлением инстинктивной социальной мобилизации может выступать запрос на силу авторитарной власти, на упрощающую мир иррациональную унификацию традиции. Тем более, что медикализация социальной жизни в условиях пандемии сопровождается ростом авторитарной по своей природе власти врачей. На исходе 2020 г. М.К. Горшков обратил внимание на эту тенденцию: «Сейчас в общественном сознании резко вырос, буквально взлетел запрос на "сильную власть”». С 26 \% два года назад - до $40 \%$ сейчас» [Четверикова web]. Связь конспирологических объяснений пандемии, религиозности и правых идеологий отмечают и психологи [Радина, Балакина 2020, 55].

В то же время ориентация на авторитаризм и консерватизм не является абсолютной, дополняясь стремлением к справедливости, демократии и гражданскому участию. В условиях пандемии понятие справедливости на- сыщается неэкономическим содержанием: возникает вопрос о справедливом доступе к социальным благам. Электронные средства коммуникации, спрямляя опосредованные социальные связи, открывают возможности для непосредственного социально-политического взаимодействия гражданина и представителей власти, вполне в духе непосредственной демократии и коммунального самоуправления. Социологи указывают также на заметное усиление требования «компетентного управления», которое должно найти баланс между жесткими мерами социальной изоляции и смягчением ее последствий. В этой связи весьма интересна оценка экономиста и политика Ж. Аттали, согласно которой новая постковидная социальная система «не будет основана ни на вере, ни на силе, ни даже на разуме... Политическая власть будет принадлежать тем, кто может проявить наибольшее сочувствие к другим» [Метелкина web].

Как видим, ответ российского общества на вызовы социальной изоляции вполне согласуется с тенденциями адаптации современных обществ к опасности глобальной пандемии. Этот ответ неоднороден: в нем обозначаются различные варианты и стратегии самосохранения. Их селекция и эффективное использование определяются, с одной стороны, трансформацией социальных институтов и ориентациями элиты общества. С другой же, они обусловлены зрелостью личности, ее готовностью развивать и совершенствовать себя, жить в «обществе риска», способностью делать адекватный выбор и нести за него ответственность. Такая способность не является лишь благим пожеланием: она, хоть и недостаточно, проявлена в современном российском обществе. Обратившись к анализу причин солидарного поведения, взаимопомощи и социальной активности россиян, мы видим среди приоритетных мотивов желание чувствовать себя полезными (45\%), возможность участвовать в решении общих проблем (31\%), реализовать себя и свои инициативы (17\%) [Солидарность на фоне пандемии... web].

В теоретическом плане поиск оптимальных вариантов социального ответа на глобальные экологические вызовы связан с трансформацией доминирующего в российском обществе типа личности. По словам В.Б. Пасту- 
хова, этот тип, будучи проявлением культуры «победившей индивидуальности», является преимущественно атомизированным индивидом, в подсознании которого живут авторитарно-сервильные, патерналистские установки, а не личностью, способной к активным, солидарным и ответственным социальным действиям [Пастухов 2011, 116]. В ходе этой трансформации доминирующий тип атомизированного индивида, соответствующий больше императивам раннего модерна, должен заместиться многомерным по своим характеристикам, ассоциированным и в то же время автономным типом личности, способным гармонизировать свои взаимодействия с природной и социально-культурной средой. Его богатство содержания, способность к самоорганизации и рефлексии должны приблизиться к соответствию сложности, динамизму и неоднозначности современного общества.

\section{СПИСОК ЛИТЕРАТУРЫ}

Каким мир станет... web - Каким мир станет после пандемии: прогнозы современных философов. Джорджо Агамбен о дискурсе чрезвычайного положения // https://snob-ru.turbopages. org/ snob.ru/s/entry/191734/.

Кукарцева (Гласер), Ивлев, Новик 2021 - Кукариева (Гласер) М.А, Ивлев В.Ю., Новик Н.Н. Дискурсы биополитики и безопасности человека в условиях новых вызовов и угроз человечеству // Вопросы философии. 2021. № 2. С. 42-52.

Лескова web - Лескова $H$. Человек разобщенный: жизнь после пандемии. Интервью с Р. Г. Апресяном // https://scientificrussia.ru/articles/ chelovek-razobshchennyj-zhizn-posle-pandemii.

Метелкина web - Метелкина C. Карантин Фуко: оценка коронавируса философами «слева» // https://www.geopolitica.ru/article/karantinfuko-ocenka-koronavirusa-filosofami-sleva.

Пастухов 2011 - Пастухов В.Б. Государство раскольников. Карма российской власти // Общественные науки и современность. 2011. № 5. С. 105-117.

Покровский, Макшанчикова, Никишин 2020-Покровский Н.Е., Макшанчикова А.Ю., Никишин Е.А. Обратная миграция в условиях пандемического кризиса: внегородские пространства России как ресурс адаптации // Социологические исследования. 2020. № 12. С. 54-64.

Радина, Балакина 2020 - Радина Н.К., Балакина Ю.В. Общество и пандемия: теоретико-методоло- гические основания психологических исследований // Общественные науки и современность. 2020. № 6. С. 49-64.

Рубцов 2020 - Рубцов А.В. Вирусы и цивилизации. О новом влиянии биокатаклизмов на эволюцию социокультурных моделей и цивилизационных проектов // Вопросы философии. 2020. № 8. C. $20-31$.

Савчук 2020 - Савчук В.В. Медиаобразование эпифеномен цифровизации // Вопросы философии. 2020. № 5. С. 83-86.

Солидарность на фоне пандемии... web - Солидарность на фоне пандемии. Аналитический обзор [ВЦИОМ] // https://wciom.ru/analyticalreviews/analiticheskii-obzor/solidarnost-nafone-pandemii.

Четверикова web - Четверикова A. Окна с видом на COVID. Социологи вышли с удаленки, чтобы узнать мнение россиян о последствиях коронавируса // https://rg.ru/2020/11/05/sociologiuznali-mnenie-rossiian-o-posledstviiahkoronavirusa.html.

Шипилов 2020 - Шипилов А.В. Возвращение домой. Заметки из самоизоляции // Социологические исследования. 2020. № 8. С. 135-144.

Habermas web-HabermasJ. 30 Jahre danach: Die zweite Chance Merkels europapolitische Kehrtwende und der innerdeutsche Vereinigungsprozess von Jürgen Habermas // https://www.blaetter.de/ ausgabe/2020/september/30-jahre-danach-diezweite-chance.

\section{REFERENCES}

What the World Will Become After the Pandemic: Forecasts of Modern Philosophers. Giorgio Agamben on the State of Emergency Discourse. URL: https://snob-ru.turbopages.org/snob.ru/s/ entry/191734/.

Kukartseva(Glaser) M.A, Ivlev V.Yu., Novik N.N., 2021. Discourses of Biopolitics and Human Securityin the Context of New Challenges and Threats to Humanity. Voprosy filosofii, no. 2, pp. 42-52.

Leskova N.A Disunited Man: Life After a Pandemic. Interview with R.G. Apressyan. URL: https://scientificrussia.ru/articles/ chelovek-razobshchennyj-zhizn-poslepandemii.

Metelkina S. Foucault Under Quarantine: Coronavirus Viewed From "The Left". URL: https:// www.geopolitica.ru/article/karantin-fukoocenka-koronavirusa-filosofami-sleva.

Pastuhov V.B., 2011. The State of the Schismatics. Karma of the Russian Government. Obshchestvennye nauki i sovremennost, no. 5, pp. 105-117. 
Pokrovsky N.E., Makshanchikova A.Yu., Nikishin E.A., 2020. Reverse Migration in Pandemic Crisis: Russia's Out-of-Town Spaces as an Adaptation Resource. Sotsiologicheskie issledovaniia, no. 12, pp. 54-64.

Radina N.K., Balakina J.V., 2020. Societyand the Pandemic: Theoretical and Methodological Foundations of Psychological Research. Obshchestvennye nauki $i$ sovremennost, no. 6, pp. 49-64.

Rubtsov A.V., 2020. The New Impact of Biocataclysms on the Evolution of Sociocultural Models and Civilization Projects. Voprosyfilosofii, no. 8, pp. 20-31.

Savchuk V.V., 2020. Media Education - Epifenomen of Digitalization. Voprosy filosofii, no. 5, pp. 83-86.

Solidarity Amid the Pandemic. Analytical Review. URL: https://wciom.ru/analytical-reviews/ analiticheskii-obzor/solidarnost-na-fonepandemii.

Chetverikova A. Windows Overlooking COVID. Sociologists Leave Remote Working to Find Out the Opinion of Russians on the Consequences of Coronavirus. URL: https://rg.ru/2020/11/05/ sociologi-uznali-mnenie-rossiian-oposledstviiah-koronavirusa.html.

Shipilov A.V., 2020. Homecoming. Notes from SelfIsolation. Sotsiologicheskie issledovaniia, no. 8, pp.135-144.

Habermas J. 30 Years Later: The Second Chance. Merkel's Turn in European Politics and Internal Process of German Unification. URL: https://www.blaetter.de/ausgabe/2020/ september/30-jahre-danach-die-zweite-chance.

\section{Information About the Author}

Alexander L. Strizoe, Doctor of Sciences (Philosophy), Professor, Department of Sociology and Social Technologies, Volgograd State University, Prosp. Universitetsky, 100, 400062 Volgograd, Russian Federation, strizoe@volsu.ru, https://orcid.org/0000-0002-3241-0480

\section{Информация об авторе}

Александр Леонидович Стризое, доктор философских наук, профессор кафедры социологии и социальных технологий, Волгоградский государственный университет, просп. Университетский, 100, 400062 г. Волгоград, Российская Федерация, strizoe@volsu.ru, https://orcid.org/0000-0002-3241-0480 